\title{
Kisemlösök faunisztikai felmérése Somogy megye északkeleti részén, gyöngybagoly Tyto alba (Scopoli, 1769) köpetek vizsgálata alapján
}

\author{
PURGER J. JENŐ \\ Pécsi Tudományegyetem, Természettudományi Kar, Biológiai Intézet, Állatökológia Tanszék, \\ H-7624 Pécs, Ifjúság útja 6., e-mail: purger@gamma.ttk.pte.hu
}

\begin{abstract}
PURGER J. J.: Small mammal fauna survey in north-eastern part of Somogy county (Hungary), based on Barn Owl Tyto alba (Scopoli, 1769) pellet analysis.

Abstract: Pellets were collected between 1999 and 2009, from 20 localities (investigated area: BT80, BS79, BS78, BS77, BS89 and BS88, according to $10 \times 10 \mathrm{~km}$ UTM grids). In a total of 1570 Barn Owl pellets there were 4127 prey remnants. Small mammals were dominating (97.8\%). 22 mammal species were evidented: Crocidura leucodon, C. suaveolens, Sorex araneus, S. minutus, Neomys anomalus, Talpa europaea, Eptesicus serotinus, Muscardinus avellanarius, Microtus agrestis, M. arvalis, M. oeconomus, M. subterraneus, Arvicola amphibius, Myodes glareolus, Apodemus agrarius, A. flavicollis, A. sylvaticus, A. uralensis, Micromys minutus, Mus musculus, M. spicilegus, Rattus norvegicus). Remnants of birds, amphibians and insects consisted $2.2 \%$ of total prey.
\end{abstract}

Keywords: diet, distribution, Soricomorpha, Chiroptera, Rodentia

\section{Bevezetés}

A Dél-dunántúli régió emlősfaunájáról országos viszonylatban is jelentős ismeretanyaggal rendelkezünk (BıHARı et al. 2007), ami részben annak köszönhető, hogy Somogy megye területén szerteágazó emlőstani kutatások folytak (LANSZKI \& PURGER 2001) és jelenleg is folynak. A leírtak ellenére vannak még hiányosságok, például a megye északkeleti részén előforduló kisemlősökről alig van publikált adat. Balatonszabadinál 1971-ben gyűjtött erdei fülesbagoly (Asio otus) köpetekből négy kisemlős faj, a mezei pocok (Microtus arvalis), a földi pocok (Microtus subterraneus), a törpeegér (Micromys minutus) és a házi egér (Mus musculus) egyedeinek maradványai kerültek elő (ScHMIDT 1974a, 1974b, 1976). Tab mellett 1983-ban egy elhagyott pajtában és gabonaraktárban gyűjtött gyöngybagoly (Tyto alba) köpetekből a mezei pocok és a földi pocok mellet az erdei cickány (Sorex araneus), a törpe cickány (Sorex minutus) és az erdei egér (Apodemus sp.) jelenlétét is kimutatták (NAGY 1988). Az idézett munkák alapján a megye északkeleti részén tehát mindössze hat kisemlős faj (és valamelyik erdeiegér faj) előfordulásáról van tudomásunk. Magyarország emlőstani atlaszában (BIHARI et al. 2007) a vizsgált területen belül a felsorolt fajokon kívül még néhány kisemlős faj elterjedési térképén találunk előfordulási pontokat. Ezek szintén bagolyköpetekből származó adatok (Tengőd, Som, Ádánd, Siójut), melyek az atlasz készítése során még nem voltak publikálva és jelen dolgozatban lesznek leközölve. A bagolyköpet vizsgálatok hatékony indirekt módszerei a kisemlős fauna felméréseknek, és Magyarországon e módszer alkalmazásának komoly hagyománya van (pl. Schmidt 1967, Kalivoda 1999, BiHARI et al. 2007). Somogy megye kisemlős faunájának eddigi szisztematikus felmérése során a gyöngybaglyok köpeteinek begyűjtését és vizsgálatát alkalmaztuk és eddig több mint 16 ezer köpetet dolgoztunk fel, melyekből közel 49 ezer kisemlős maradványai kerültek elő (PURGER 1996, 1997, 1998, 2002, 2004, 2005, 2008).

A megye északkeleti részén előforduló kisemlős fajok jelenlétéről, gyakoriságáról, elterjedéséről nagyon keveset tudunk, ezért a munka célja az volt, hogy gyöngybagoly köpetek begyűjtésével és vizsgálatával elvégezzük a vizsgált terület kisemlős faunájának alapállapot felmérését.

\section{Anyag és módszerek}

A kisemlös fauna felmérések egyik leghatékonyabb módszere a gyöngybaglyok köpeteinek begyűjtése és vizsgálata (SCHMIDT 1967, MIKUSKA et al. 1979). A baglyok költő- és pihenőhelyein ugyanis többnyire nagy mennyiségü köpet gyüjthető, és a bennük épségben megmaradt koponyák, állkapcsok, fogak alapján az egyes emlősfajok egyedei jól elkülöníthetők egymástól (SchmidT 1967).

A faunisztikai (biotikai) adatok kompatibilitása érdekében (DÉVAl et al. 1997), a bagolyköpet gyűjtések, azaz a kisemlős fauna felmérések $10 \times 10 \mathrm{~km}$-es UTM rendszerü hálótérképek (Mıskolczı et al. 1997) alapján, az egyes mezőknek, ill. négyzeteknek megfelelő területeken folytak. A köpetek 1999 és 2009 között hat UTM négyzet (BT80, BS79, BS78, BS77, BS89, BS88) által lefedett területről (1. ábra), 20 lelőhelyről lettek begyűjtve (1. táblázat). Egyes lelöhelyeken többször is folyt gyüjtés, így összesen 38 minta (1570 köpet) lett feldolgozva (1. táblázat). A vizsgált terület bejárását, valamint a köpetek gyűjtését Szinai Péter (SzP), Tóth Tamás (TT) és a Gyöngybagolyvédelmi Alapítvány (GyA) munkatársai végezték (1. táblázat).

Csak az egész köpetek lettek feldolgozva és mivel többségük korát nem lehetett biztosan meghatározni, a megadott dátumok csak a gyüjtés idejét jelzik (1. táblázat). Szétbontásukat száraz technikával végeztük (Schmidt 1967, MıkUSkA et al. 1979). A kisemlősök meghatározása csonttani bélyegek alapján történt (Ács 1985, KRYŠTUFEK 1985, 1991, KRYŠTUFEK \& JANŽEKOVIČ 1999, März 1972, Niethammer \& Krapp 1978, 1982, 1990 , SCHMIdT 1967, UJHelYI 1989, ZöRÉNYI 1990, YALDEN 1977, 


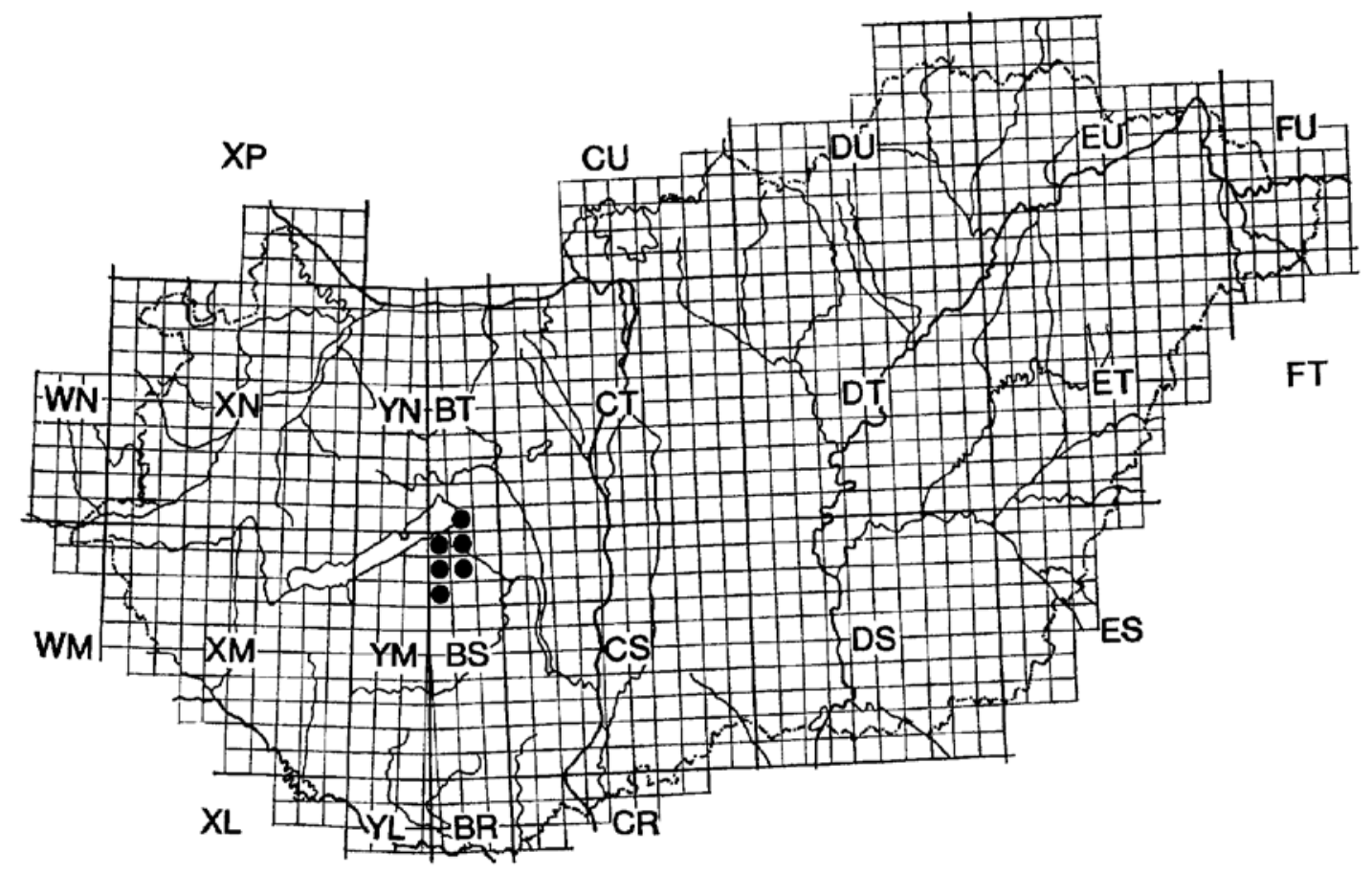

1. ábra: A vizsgált terület elhelyezkedése Magyarország UTM rendszerü hálótérképén.

Figure 1: Situation of the investigated area in the UTM grid map of Hungary.

YALDEN \& MoRris 1990). A Sylvaemus szubgénuszba tartozó fajok meghatározásánál TVRTKović (1979) módszerét követtük. A koponya sérülései miatt meghatározhatatlan példányok, mint Apodemus sp. szerepelnek a táblázatokban (2a., 2b., 2c., 3. táblázat). A Neomys génuszba tartozó két faj, a közönséges vízicickány (Neomys fodiens) és a Miller-vízicickány (Neomys anomalus) meghatározását TVRTKović et al. (1980) által leírt módon végeztük. A házi egér (Mus musculus) és güzüegér (Mus spicilegus) elkülönítésénél MACHOLÁN (1996) határozókulcsát használtuk. A Mus és Rattus génuszba tartozó, nehezen határozható vagy sérült példányok, mint Mus sp. és Rattus sp. kerültek a fajlistákra (2a., 2b., 2c., 3. táblázat). Az emlősfajok tudományos és magyar neveit BıHARı et al. (2007) munkája alapján használtuk.

\section{Eredmények és értékelés}

A vizsgált területen a gyöngybagoly köpetek lelöhelyei 17 esetben (85\%) egyházi épületek (templomok tornyai és padlásai), 3 esetben (15\%) lakóház és gazdasági épületek voltak (1. táblázat). Összesen 1570 köpetet gyűjtöttünk be, melyekből 4127 zsákmányállat maradványai kerültek elő (1. táblázat). Egy köpet átlagosan 2,6 zsákmány maradványait tartalmazta.

A területen élő gyöngybaglyok táplálékában a kisemlősök domináltak $(97,8 \%)$. A zsákmány mindössze 2,2\%-át alkották madár-, kétéltü- és rovarmaradványok (2a., 2b., 2c. táblázat). A szétbontott köpetekből 22 kisemlős faj 4036 egyedének maradványai kerültek elő (3. táblázat).
A gyöngybaglyok emlőstáplálékának 17,2\%-át a cickányalakúak (Soricomorpha), 0,02\%-át a denevérek (Chiroptera), 82,8\%-át a rágcsálók (Rodentia) rendjébe sorolt fajok egyedei alkották.

A köpetekböl kimutatott 5 cickányfaj közül a vizsgált területen a keleti cickány (Crocidura suaveolens) és az erdei cickány (Sorex araneus) volt a leggyakoribb. A mezei cickány (Crocidura leucodon) az előző fajoknál kisebb számban, de minden UTM négyzet területén elöfordult. A törpe cickány (Sorex minutus) maradványai a BS79-es a Miller-vízicickány (Neomys anomalus) maradványai viszont a BT80 és a BS77-es UTM négyzet kivételével, kis egyedszámmal, de szinte mindenhonnan előkerültek (3. táblázat). A közönséges vízicickányt (Neomys fodiens) a vizsgált területről nem sikerült kimutatnunk. Az emlőstani irodalomból eddig csak két cickányfaj ( $S$. araneus és S. minutus) elöfordulásáról volt tudomásunk Tab (BS77) térségéből (NAGY 1988), így e munka eredményei az említett fajokon kívül három újabb cickányfaj (C. leucodon, C. suaveolens, $N$. anomalus) elöfordulási adataival gazdagítják ismereteinket.

A közönséges vakond (Talpa europaea) az ország egész területén megtalálható, gyakori faj (BIHARI 2007a), de életmódja miatt ritka zsákmánya a gyöngybaglyoknak és elterjedési adatokban sem bővelkedünk. Aközönséges vakond maradványai csak Ádánd (BS89), Nagyberény (BS88) és Bábonymegyer (BS88) környékéröl származó köpetekből kerültek elő (1, 2b, 2c. táblázat).

A gyöngybaglyok költő-, illetve pihenőhelyéül szolgáló padlások, tornyok gyakran az épületlakó denevérek lakhelye is, így előfordul, hogy egy-egy denevért is zsákmányolnak. A közönséges késeidenevér (Eptesicus 
serotinus) maradványai Nagyberényből (BS88) kerültek elö (1., 2c. táblázat). A denevérek részesedése a gyöngybaglyok táplálékában általában elenyésző, a leletek faunisztikai jelentősége nem elhanyagolható még akkor sem, ha az ország egyik legegyenletesebben elöforduló denevérfajáról van Szó (BIHARI 2007b).

A mogyorós pelék (Muscardinus avellanarius) is ritka zsákmányai a gyöngybaglyoknak, ennek ellenére a faj elterjedési mintázatának vizsgálata során a köpetelemzések rengeteg információval szolgáltak. A vizsgált térségben négy UTM négyzet területén gyűjtött köpetekből (BS79, BS78, BS89, BS88) sikerült kimutatnunk több példányát (3. táblázat). A Balaton környékéről alig van e faj elterjedését igazoló publikált adat (BAKó 2007), így ezek az eredmények nagyban hozzájárulnak az ország területén élő mogyorós pelék elterjedésének megismeréséhez.

A gyöngybaglyok emlőszsákmányának több mint $80 \%$-a rágcsáló (Rodentia) volt. Amezei pocok (Microtus arvalis), mint az ország egyik leggyakoribb emlősfaja, a vizsgált területen is igen gyakorinak számít, amit az is igazol, hogy a gyöngybaglyok szinte minden második rágcsáló zsákmánya mezei pocok volt! A hörcsögfélék (Cricetidae) kiemelkedően magas százalékos részesedése (az emlőszsákmány 48,4\%-a) elsősorban a mezei pocok nagyszámú egyedének köszönhető. A hörcsögfélék (Cricetidae) közül a mezei pockon kívül, kisebb egyedszámmal, de az egész vizsgált területről a földi pocok (Microtus subterraneus) és a vöröshátú erdeipocok (Myodes glareolus) egyedei is elökerültek (3. táblázat). Az emlőstani irodalomból eddig csak a mezei pocok és a földi pocok (BS77, BS89) helyi jellegü előfordulásáról volt tudomásunk (SCHMIDT 1974a, 1974b, 1976, NAGY 1988), tehát jelen előfordulási adatok kiegészítik a fajok elterjedésével kapcsolatos ismereteinket. A csalitjáró pocok (Microtus agrestis) egy UTM négyzet kivételével (BT80) mindenütt kimutatható volt, a közönséges kószapocok (Arvicola amphibius) előfordulási mintázata viszont egyenetlen eloszlásra utal (3. táblázat). Az Ádándon (BS89) gyüjtött köpetekből egy északi pocok (Microtus oeconomus) koponyamaradványai is előkerültek (1., 2b. táblázat). Annak ellenére, hogy csak a köpet lelöhelye ismert és nem tudhatjuk pontosan, hogy a bagoly hol zsákmányolta az északi pockot, az adat jelzés értékű. Valószínűsíthető, hogy ez a kisemlős faj a Balaton déli partja mentén a jelenleg ismert elterjedési területén (GuBÁNYI 2007) kívül is előfordul (lásd pl. PuRger 2008).
A vizsgált területen élő egérfélék (Muridae) közül nyolc faj nagyszámú egyede (az emlőszsákmány 34,4\%-a) került elő (3. táblázat). A pirók erdeiegér (Apodemus agrarius), a sárganyakú erdeiegér (Apodemus flavicollis) és a közönséges erdeiegér (Apodemus sylvaticus) egyedek fontos zsákmányai a gyöngybaglyoknak és az egész térségben gyakori kisemlősöknek tekinthetők (3. táblázat). A kislábú erdeiegér (Apodemus uralensis) Somogy megyei előfordulásáról a múlt században nem volt tudomásunk (LANSZKI \& PURGER 2001), de az elmúlt évtizedben több helyről is sikerült kimutatni (PURGER 2008). A vizsgált területen két egyed maradványai kerültek elő Ádándon (BS89), és egy egyed maradványai Nagyberényben (BS88) gyüjtött köpetekből (2b., 2c. táblázat). Az újabb lelőhelyek fontosak a kislábú erdeiegér dél-nyugati elterjedési határának pontos meghatározása szempontjából (CSERKÉsz 2005).

A törpeegér (Micromys minutus) és a házi egér (Mus musculus) Balatonszabadi előfordulásáról már tudtunk (ScHMidT 1976). Eredményeink azonban arra utalnak, hogy a törpeegér igaz kis egyedszámmal, de az egész vizsgált területen előfordul. A házi egér és a güzüegér (Mus spicilegus) pedig gyakori fajai a térségnek, ami nagy valószínűséggel a vándorpatkányról (Rattus norvegicus) is elmondható annak ellenére, hogy ez utóbbi faj egyedeit nem mutattuk ki minden UTM négyzetből (1. 3. táblázat).

Eredményeink 22 kisemlős faj elöfordulási adataival gazdagítják Somogy megye emlősfaunájának ismeretanyagát. Fontos eredmény a kislábú erdeiegér újabb előfordulásainak dokumentálása, valamint az északi pocok maradványainak előkerülése Ádánd környékéröl.

\section{Köszönetnyilvánítás}

Köszönöm Szinai Péternek, Tóth Tamásnak és a Gyöngybagolyvédelmi Alapítvány munkatársainak a köpetek begyűjtésénél, Dr. Csorba Gábornak a denevérek meghatározásánál, Dr. Bihari Zoltánnak az emlöstani irodalom összegyüjtésénél, Légvári Katalinnak és Purger Eleonorának pedig a köpetek tisztításában nyújtott segítséget. 


\section{Irodalom}

Ács, A. 1985: A bagolyköpetvizsgálatok alapjai. - A Magyar Madártani Egyesület Zalai Helyi Csoportjának kiadványa, Zalaegerszeg, $58 \mathrm{pp}$.

BAKó, B. 2007: Mogyorós pele. - Pp. 146-147. In: BiHARI, Z., CsorbA, G. \& HeLtAl, M. (ed.): Magyarország emlőseinek atlasza. Kossuth Kiadó, Budapest. pp. 360

BIHARI, Z. 2007a: Közönséges vakond. - Pp. 67-68. In: BIHARI, Z., CsoRBA, G. \& HeLtAI, M. (ed.): Magyarország emlöseinek atlasza. Kossuth Kiadó, Budapest. pp. 3-60.

BIHARI, Z. 2007b: Közönséges késeidenevér. - Pp. 81-82. In: BIHARI, Z., CsoRBA, G. \& HeLtAI, M. (ed.): Magyarország emlőseinek atlasza. Kossuth Kiadó, Budapest. pp. 360.

BIHARI, Z., CsoRBA, G. \& HeLTAI, M. (ed.) 2007: Magyarország emlöseinek atlasza. - Kossuth Kiadó, Budapest. pp. 360

CSERKÉSz, T. 2005: Bagolyköpetekböl származó erdeiegér (Sylvaemus subgenus, Rodentia) koponyamaradványok összehasonlitó kraniometriai vizsgálata: a fajok elkülönítése és a korcsoportok szerepe. - Állattani Közlemények 90: 41-55.

DÉvAl, Gy., Mıskolczı, M. \& Tóth, S. 1997: Egységesítési javaslat a névhasználatra és az UTM rendszerü kódolásra a biotikai adatok lelöhelyeinél. - Acta Biologica Debrecina Supplementum Oecologica Hungarica 8: 13-42.

GubÁnYı, A. 2007: Északi pocok. Pp. 164-165. In: BirarI, Z., Csorba, G. \& HeLtAl, M. (ed.): Magyarország emlőseinek atlasza. Kossuth Kiadó, Budapest. pp. 360

KALIVODA, B. 1999. A magyar bagoly-táplálkozástani irodalom annotált bibliográfiája. - Crisicum 2: 221-254.

KRYŠtufEK, B. 1985: Mali sesalci. - Naša rodna zemlja 4. Prirodoslovno društvo Slovenije, Ljubljana, $30 \mathrm{pp}$.

KRYŠtufEK, B. 1991: Sesalci Slovenije. - Prirodoslovni muzej Slovenije, Ljubljana, $294 \mathrm{pp}$.

KRYŠtuFEK, B. \& JANŽEKovič, F. (ed.) 1999: Ključ za določanje vetenčarjev Slovenije. - DZS, Lubljana, $544 \mathrm{pp}$.

Lanszki, J. \& Purger, J. J. 2001: Somogy megye emlös faunája (Mammalia). - Natura Somogyiensis 1: 481-494.

MACHOLÁN, M. 1996: Key to European house mice (Mus). - Folia Zoologica 45(3): 209-217.

MÄrz, R. 1972: Gewöll- und Rupfungskunde. -Akademie Verlag, Berlin, $398 \mathrm{pp}$.

Mikuska, J., TVRTKović, N. \& Džukı́́, G. 1979: Sakupljanje i analiza gvalica ptica kao jedna od važnih metoda upoznavanja faune naših sisara. - Arhiv bioloških nauka 29(3-4): 157-160.

Mıskolczı, M., Déval, Gy., Kertész, Gy. \& BAJZA, Á. 1997: A magyarországi helységek kódjegyzéke az UTM rendszerủ $10 \times 10 \mathrm{~km}$ beosztású hálótérkép szerint. Acta Biologica Debrecina Supplementum Oecologica Hungarica 8: 43-194.

NAGY, S. 1988. Gyöngybagoly (Tyto alba) táplálkozási adatok a Dunántúlról. - Madártani Tájékoztató 1988 január-december: 92-95.

Niethammer, J. \& KRAPP, F. (ed.) 1978: Handbuch der Säugetiere Europas. - Band 1. Nagetiere I. Akademische Verlagsgesellschaft, Wiesbaden, $476 \mathrm{pp}$.

Niethammer, J. \& KRApP, F. (ed.) 1982: Handbuch der Säugetiere Europas. - Band 2/l. Nagetiere II. Akademische Verlagsgesellschaft, Wiesbaden. $649 \mathrm{pp}$.

Niethammer, J. \& KRapP, F. (ed.) 1990: Handbuch der Säugetiere Europas. - Band 3/I. Insektenfresser, Herrentiere. AULA-Verlag, Wiesbaden. $523 \mathrm{pp}$.
PURGER, J. J. 1996: A Boronka-melléki Tájvédelmi Körzet keleti határvidékének (Somogy megye) kisemlös faunája, gyöngybagoly, Tyto alba (Scopoli, 1769) köpetek vizsgálata alapján. - Somogyi Múzeumok Közleményei 12: 299-302.

PURGER, J. J. 1997: A csokonyavisontai halastavak (Somogy megye) környékének kisemlös faunája, gyöngybagoly köpetek vizsgálata alapján. - Természetvédelmi Közlemények 5-6: 105-109.

PuRger, J. J. 1998: A Dráva mente Somogy megyei szakaszának kisemlös (Mammalia) faunája, gyöngybagoly, Tyto alba (Scopoli, 1769) köpetek vizsgálata alapján. - Dunántúli Dolgozatok (A) Természettudományi Sorozat 9: 489-500.

PURGer, J. J. 2002: A Somogyszob, Hajmás és Kálmáncsa közötti térség kisemlös faunája, gyöngybagoly Tyto alba (Scopoli, 1769) köpetek vizsgálata alapján. - Natura Somogyiensis 3: 99-110.

Purger, J. J. 2004: Varászló, Somogysárd, Iharos és Csököly környékének, valamint az általuk határolt térség (Somogy megye) kisemlös faunája, gyöngybagoly Tyto alba (Scopoli, 1769) köpetek vizsgálata alapján. - Somogyi Múzeumok Közleményei 16: 409419.

PURGeR, J. J. 2005: Kaposvár és környékének (Somogy megye) kisemlös faunája, gyöngybagoly Tyto alba (Scopoli, 1769) köpetek vizsgálata alapján. - Folia Historico-naturalia Musei Matraensis 29: $203-215$

PURGeR, J. J. 2008: Öreglak, Kürtöspuszta, Törökkoppány és Kazsok környékének (Somogy megye), valamint az általuk határolt térség kisemlösfaunájának vizsgálata, gyöngybagoly- (Tyto alba (Scopoli, 1769)) köpetek alapján. - Állattani Közlemények 93: 65-76.

SCHMIDT, E. 1967: Bagolyköpet vizsgálatok. - Magyar Madártani Intézet. Budapest, $137 \mathrm{pp}$.

ScHmid, E. 1974a. A magyarországi mezeipocok- (Microtus arvalis) állomány relatív sürüsége 1969-71-ben bagolyköpetek vizsgálata alapján. - Aquila 78-79: 189-196.

SchmidT, E. 1974b. Über die Verbreitung und Wohndichte der Kleinwühlmaus (Pitymys subterraneus [De Selys-Longchamps]) in Ungarn. - Vertebrata Hungarica 15: 45-52.

SснміDт, E. 1976. Kleinsägerfaunistische Daten aus Eulengewöllen in Ungarn. - Aquila 82: 119-144.

TVRTKović, N. 1979: Razlikovanje i određivanje morfološki sličnih vrsta podroda Sylvaemus Ognev \& Vorobiev 1923 (Rodentia, Mammalia). - Rad JAZU 383: 155-186.

TVRTKović, N., Đulić, B. \& Mrakovčıć, M. 1980: Distribution, species characters, and variability of the Southern water-shrew, Neomys anomalus Cabrera, 1907 (Insectivora, Mammalia) in Croatia. -Biosistematika 6(2): 187-201.

UJHELYI, P. 1989: A magyarországi vadonélö emlösállatok határozója (Küllemi és csonttani bélyegek alapján). - A Magyar Madártani és Természetvédelmi Egyesület (MME) Könyvtára 1. Budapest, $185 \mathrm{pp}$.

Yalden, D. W. 1977: The Identification of remains in Owl Pellets. - An Occasional Publication of the Mammal Society No. 2. Reading, $8 \mathrm{pp}$.

Yalden, D. W. \& Morris, P. A. 1990: The Analysis of Owl Pellets. - An Occasional Publication of the Mammal Society No. 13. London, $24 \mathrm{pp}$.

ZöRÉNYI, M. 1990: A bagolyköpetekböl várható hazai emlösfajok határozókulcsa. - Babits füzetek 1. Babits Mihály Múvelödési Központ, Szekszárd. $34 \mathrm{pp}$. 
1. táblázat: $A$ különböző lelőhelyeken gyüjtött köpetek és az előkerült zsákmányállatok száma. Table 1: Number of pellets and their prey contents, collected in different localities.

\begin{tabular}{|c|c|c|c|c|c|c|}
\hline No. & $\begin{array}{l}\text { Lelöhely } \\
\text { Locality }\end{array}$ & UTM & $\begin{array}{l}\text { Dátum } \\
\text { Date }\end{array}$ & $\begin{array}{c}\text { Gyüjtök } \\
\text { Collectors }\end{array}$ & $\begin{array}{l}\text { Köpet } \\
\text { Pellet }\end{array}$ & $\begin{array}{c}\text { Zsákmány } \\
\text { Prey }\end{array}$ \\
\hline 01 . & Gamászapuszta (kat. temp.) & BT 80 & 2009.07 .12 . & $\mathrm{SzP}, \mathrm{TT}$ & 19 & 52 \\
\hline 02. & Siófok, Töreki (lovarda) & BS79 & 2009.06 .24 . & SzP, TT & 36 & 72 \\
\hline 03a. & Ságvár (kat. temp.) & BS79 & 2000.09 .30 . & GyA & 46 & 109 \\
\hline $03 \mathrm{~b}$. & Ságvár (kat. temp.) & BS79 & 2002.11 .10 & GyA & 43 & 122 \\
\hline 04. & Ságvár (ref. temp.) & BS79 & 2002.11.10. & GyA & 58 & 150 \\
\hline $05 \mathrm{a}$. & Nyím (kat. temp.) & BS78 & 2001.07 .21 . & GyA & 67 & 194 \\
\hline $05 \mathrm{~b}$. & Nyím (kat. temp.) & BS78 & 2002.11.10. & GyA & 27 & 87 \\
\hline 06. & Lulla, Jabapuszta (magtár) & BS78 & 2009.06 .24 & SzP, TT & 28 & 48 \\
\hline 07. & Torvaj (eva. temp) & BS78 & 2000.07 .03 . & GyA & 22 & 62 \\
\hline 08. & Sérsekszőlős (temető harangláb) & BS78 & 2000.07 .05 . & GyA & 49 & 156 \\
\hline 09a. & Kánya (kat. temp.) & BS77 & 2002.07 .29 . & GyA & 17 & 37 \\
\hline $09 b$. & Kánya (kat. temp.) & BS77 & 2002.11.10. & GyA & 40 & 91 \\
\hline $10 \mathrm{a}$. & Tengőd (ref. temp.) & BS77 & 1999.06.23. & GyA & 71 & 227 \\
\hline $10 \mathrm{~b}$. & Tengőd (ref. temp.) & BS77 & 2000.07 .02 . & GyA & 60 & 144 \\
\hline $10 \mathrm{c}$. & Tengőd (ref. temp.) & BS77 & 2001.07 .21$. & GyA & 31 & 65 \\
\hline $10 \mathrm{~d}$. & Tengőd (ref. temp.) & BS77 & 2002.07 .30 . & GyA & 45 & 78 \\
\hline $10 \mathrm{e}$. & Tengőd (ref. temp.) & BS77 & 2002.11.10. & GyA & 46 & 113 \\
\hline & Bedegkér (eva. temp.) & BS77 & 2000.09 .29 . & GyA & 28 & 101 \\
\hline $12 \mathrm{a}$. & Siójut (ref. temp.) & BS89 & 1999.02.10. & GyA & 10 & 29 \\
\hline $12 b$. & Siójut (ref. temp.) & BS89 & 2005.07 .04 . & GyA & 95 & 222 \\
\hline 13a. & Ádánd (ref. temp.) & BS 89 & 1999.02.06. & GyA & 11 & 39 \\
\hline & Ádánd (ref. temp.) & BS 89 & 2001.07 .21$. & GyA & 43 & 80 \\
\hline $13 \mathrm{c}$. & Ádánd (ref. temp.) & BS89 & 2002.06 .21$. & GyA & 61 & 164 \\
\hline & Ádánd (ref. temp.) & BS89 & 2005.07 .04 . & GyA & 56 & 120 \\
\hline $13 \mathrm{e}$. & Ádánd (ref. temp.) & BS89 & 2005.09 .29 . & GyA & 73 & 169 \\
\hline & Ádánd (kat. temp.) & BS 89 & 2002.06 .21$. & GyA & 62 & 166 \\
\hline $15 \mathrm{a}$. & Som (ref. temp.) & BS 88 & 1999.05.22. & GyA & 39 & 138 \\
\hline $15 b$. & Som (ref. temp.) & BS 88 & 2002.06 .29 . & GyA & 25 & 77 \\
\hline 16a. & Nagyberény (kat. temp.) & BS 88 & 2000.09 .30 . & GyA & 52 & 158 \\
\hline $16 \mathrm{~b}$. & Nagyberény (kat. temp.) & BS 88 & 2009.06 .24 . & SzP, TT & 30 & 85 \\
\hline & Som, Daránypuszta (lakóház) & BS 88 & 2009.06 .24 & SzP, TT & 16 & 49 \\
\hline 18a. & Bábonymegyer (ref. temp.) & BS 88 & 2000.07 .04 . & GyA & 63 & 207 \\
\hline $18 \mathrm{~b}$. & Bábonymegyer (ref. temp.) & BS88 & 2009.06 .07$. & SzP, TT & 8 & 18 \\
\hline 19a. & Bábonymegyer (eva. temp.) & BS 88 & 2000.07 .03 . & GyA & 30 & 69 \\
\hline $19 b$. & Bábonymegyer (eva. temp.) & BS 88 & 2000.09 .30 . & GyA & 37 & 102 \\
\hline $19 c$. & Bábonymegyer (eva. temp.) & BS 88 & 2001.07 .21 . & GyA & 31 & 69 \\
\hline 19d. & Bábonymegyer (eva. temp.) & BS 88 & 2002.11 .10 . & GyA & 58 & 171 \\
\hline \multirow[t]{2}{*}{20.} & Bábonymegyer (kat. temp.) & BS 88 & 2009.06 .24 . & SzP, TT & 37 & 87 \\
\hline & Összesen - Total & & & & 1570 & 4127 \\
\hline
\end{tabular}


2 a. táblázat: $A$ köpetmintákból (01-09b) elökerült zsákmányállatok száma (a mintavételi helyek számozását az 1. táblázat tartalmazza).

Table 2 a: Number of prey specimens in pellets of Barn Owl in samples 01-09b (numbering of sampling sites are according to Table 1.).

\begin{tabular}{lrrrrrrrrrrrr}
\hline Zsákmány - Prey & 01. & 02. & $03 \mathrm{a}$. & $03 \mathrm{~b}$. & 04. & $05 \mathrm{a}$. & $05 \mathrm{~b}$. & 06. & 07. & 08. & $09 \mathrm{a}$. & $09 \mathrm{~b}$. \\
Crocidura leucodon & 1 & 2 & 0 & 4 & 7 & 10 & 12 & 0 & 0 & 0 & 6 & 7 \\
Crocidura suaveolens & 1 & 5 & 3 & 6 & 4 & 23 & 16 & 0 & 3 & 31 & 0 & 0 \\
Sorex araneus & 9 & 1 & 0 & 1 & 3 & 9 & 5 & 0 & 5 & 12 & 0 & 1 \\
Sorex minutus & 2 & 0 & 0 & 0 & 0 & 1 & 2 & 0 & 0 & 1 & 0 & 0 \\
Neomys anomalus & 0 & 0 & 1 & 0 & 0 & 1 & 0 & 0 & 3 & 0 & 0 & 0 \\
Muscardinus avellanarius & 0 & 0 & 1 & 0 & 0 & 0 & 0 & 1 & 0 & 0 & 0 & 0 \\
Microtus agrestis & 0 & 0 & 0 & 1 & 0 & 0 & 0 & 0 & 0 & 3 & 0 & 0 \\
Microtus arvalis & 19 & 24 & 30 & 71 & 91 & 53 & 30 & 7 & 26 & 79 & 11 & 69 \\
Microtus subterraneus & 3 & 3 & 6 & 2 & 12 & 14 & 2 & 0 & 2 & 0 & 3 & 3 \\
Arvicola amphibius & 0 & 0 & 0 & 1 & 0 & 0 & 0 & 0 & 0 & 0 & 0 & 0 \\
Myodes glareolus & 1 & 0 & 1 & 0 & 2 & 0 & 0 & 0 & 0 & 1 & 2 & 0 \\
Apodemus agrarius & 2 & 6 & 5 & 9 & 7 & 23 & 8 & 3 & 2 & 13 & 2 & 3 \\
Apodemus flavicollis & 2 & 11 & 4 & 5 & 4 & 9 & 4 & 9 & 7 & 0 & 3 & 1 \\
Apodemus sylvaticus & 2 & 2 & 4 & 5 & 3 & 9 & 5 & 3 & 4 & 2 & 2 & 2 \\
Apodemus sp. & 4 & 9 & 15 & 4 & 5 & 15 & 0 & 22 & 2 & 3 & 4 & 2 \\
Micromys minutus & 1 & 0 & 1 & 0 & 0 & 0 & 1 & 0 & 1 & 2 & 1 & 0 \\
Mus musculus & 1 & 4 & 3 & 5 & 2 & 11 & 1 & 1 & 1 & 1 & 3 & 2 \\
Mus spicilegus & 1 & 1 & 8 & 7 & 8 & 15 & 1 & 1 & 3 & 3 & 0 & 1 \\
Mus sp. & 1 & 1 & 0 & 0 & 0 & 1 & 0 & 0 & 0 & 0 & 0 & 0 \\
Rattus norvegicus & 0 & 0 & 9 & 0 & 0 & 0 & 0 & 0 & 0 & 0 & 0 & 0 \\
Aves (indet.) & & & & & & & & & & & & \\
Amphibia (Pelobates fuscus) & 0 & 0 & 16 & 1 & 2 & 0 & 0 & 1 & 0 & 5 & 0 & 0 \\
\hline Összesen - Total & 52 & 72 & 109 & 122 & 150 & 194 & 87 & 48 & 62 & 156 & 37 & 91 \\
\hline & & & & & & & & & & & & \\
\hline
\end{tabular}


2 b. táblázat: A köpetmintákból (10a-13e) elökerült zsákmányállatok száma (a mintavételi helyek számozását az 1. táblázat tartalmazza).

Table 2 b: Number of prey specimens in pellets of Barn Owl in samples 10a-13e (numbering of sampling sites are according to Table 1.).

\begin{tabular}{lrrrrrrrrrrrrr}
\hline Zsákmány - Prey & $10 \mathrm{a}$. & $10 \mathrm{~b}$ & $10 \mathrm{c}$. & $10 \mathrm{~d}$ & $10 \mathrm{e}$. & 11. & $12 \mathrm{a}$ & $12 \mathrm{~b}$. & $13 \mathrm{a}$ & $13 \mathrm{~b}$. & $13 \mathrm{c}$. & $13 \mathrm{~d}$. & $13 \mathrm{e}$. \\
Crocidura leucodon & 4 & 2 & 0 & 3 & 12 & 0 & 1 & 8 & 1 & 0 & 4 & 8 & 3 \\
Crocidura suaveolens & 3 & 0 & 0 & 0 & 3 & 2 & 0 & 17 & 4 & 1 & 3 & 5 & 10 \\
Sorex araneus & 30 & 8 & 1 & 0 & 2 & 15 & 2 & 5 & 1 & 0 & 0 & 0 & 2 \\
Sorex minutus & 14 & 4 & 2 & 0 & 0 & 2 & 2 & 0 & 0 & 0 & 6 & 6 & 0 \\
Neomys anomalus & 0 & 0 & 0 & 0 & 0 & 0 & 0 & 0 & 0 & 0 & 1 & 1 & 0 \\
Talpa europaea & 0 & 0 & 0 & 0 & 0 & 0 & 0 & 0 & 0 & 0 & 0 & 2 & 0 \\
Muscardinus avellanarius & 0 & 0 & 0 & 0 & 0 & 0 & 0 & 0 & 0 & 0 & 0 & 1 & 0 \\
Microtus agrestis & 0 & 0 & 1 & 0 & 0 & 2 & 0 & 0 & 0 & 2 & 1 & 0 & 0 \\
Microtus arvalis & 33 & 35 & 30 & 50 & 58 & 26 & 6 & 80 & 8 & 53 & 82 & 31 & 110 \\
Microtus oeconomus & 0 & 0 & 0 & 0 & 0 & 0 & 0 & 0 & 0 & 0 & 0 & 0 & 1 \\
Microtus subterraneus & 11 & 4 & 2 & 0 & 11 & 5 & 2 & 9 & 5 & 0 & 16 & 5 & 5 \\
Arvicola amphibius & 0 & 0 & 0 & 0 & 0 & 0 & 0 & 2 & 2 & 3 & 1 & 3 & 2 \\
Myodes glareolus & 3 & 2 & 2 & 0 & 2 & 1 & 2 & 2 & 1 & 0 & 2 & 1 & 0 \\
Apodemus agrarius & 23 & 27 & 5 & 3 & 11 & 10 & 0 & 8 & 7 & 7 & 15 & 11 & 8 \\
Apodemus flavicollis & 7 & 7 & 5 & 1 & 7 & 5 & 1 & 2 & 0 & 1 & 5 & 8 & 6 \\
Apodemus sylvaticus & 22 & 14 & 5 & 3 & 1 & 11 & 5 & 12 & 1 & 4 & 10 & 15 & 7 \\
Apodemus uralensis & 0 & 0 & 0 & 0 & 0 & 0 & 0 & 0 & 0 & 1 & 0 & 0 & 1 \\
Apodemus sp. & 21 & 14 & 6 & 12 & 3 & 12 & 1 & 10 & 3 & 5 & 11 & 9 & 9 \\
Micromys minutus & 5 & 1 & 0 & 1 & 0 & 0 & 0 & 1 & 0 & 0 & 1 & 0 & 0 \\
Mus musculus & 22 & 6 & 1 & 3 & 2 & 2 & 5 & 41 & 2 & 2 & 4 & 10 & 3 \\
Mus spicilegus & 22 & 19 & 4 & 2 & 1 & 6 & 1 & 3 & 0 & 0 & 2 & 2 & 0 \\
Mus sp. & 0 & 0 & 0 & 0 & 0 & 0 & 0 & 0 & 0 & 1 & 0 & 0 & 0 \\
Rattus norvegicus & 2 & 1 & 0 & 0 & 0 & 2 & 0 & 1 & 0 & 0 & 0 & 0 & 0 \\
Rattus sp. & 0 & 0 & 0 & 0 & 0 & 0 & 0 & 1 & 0 & 0 & 0 & 0 & 0 \\
Aves (indet.) & & & & & & & & & & & & & \\
Amphibia (Pelobates fuscus) & 5 & 0 & 1 & 0 & 0 & 0 & 1 & 8 & 2 & 0 & 0 & 0 & 0 \\
Insecta (Coleoptera) & 0 & 0 & 0 & 0 & 0 & 0 & 0 & 3 & 2 & 0 & 0 & 2 & 2 \\
\hline Összesen - Total & 227 & 144 & 65 & 78 & 113 & 101 & 29 & 222 & 39 & 80 & 164 & 120 & 169 \\
\hline & & 0 & 0 & 0 & 0 & 0 & 9 & 0 & 0 & 0 & 0 & 0 \\
\hline
\end{tabular}


2 c. táblázat: A köpetmintákból (14-20) előkerült zsákmányállatok száma

(a mintavételi helyek számozását az 1. táblázat tartalmazza).

Table 2 c: Number of prey specimens in pellets of Barn Owl in samples 14-20 (numbering of sampling sites are according to Table 1.).

\begin{tabular}{|c|c|c|c|c|c|c|c|c|c|c|c|c|c|}
\hline Zsákmány - Prey & 14. & $15 \mathrm{a}$. & $15 b$. & $16 a$. & $16 \mathrm{~b}$. & 17. & $18 \mathrm{a}$. & $18 \mathrm{~b}$. & 19a. & $19 \mathrm{~b}$. & $19 \mathrm{c}$. & $19 \mathrm{~d}$. & 20. \\
\hline Crocidura leucodon & 4 & 1 & 3 & 4 & 3 & 2 & 4 & 1 & 1 & 2 & 4 & 3 & 4 \\
\hline Crocidura suaveolens & 6 & 14 & 4 & 15 & 4 & 5 & 16 & 4 & 1 & 9 & 0 & 6 & 17 \\
\hline Sorex araneus & 11 & 11 & 3 & 23 & 6 & 6 & 29 & 0 & 1 & 6 & 1 & 10 & 2 \\
\hline Sorex minutus & 2 & 5 & 1 & 5 & 1 & 2 & 11 & 0 & 0 & 0 & 0 & 1 & ( \\
\hline Neomys anomalus & 1 & 3 & 0 & 3 & 3 & 0 & 7 & 0 & 0 & 0 & 0 & 2 & 1 \\
\hline Talpa europaea & 0 & 0 & 0 & 1 & 0 & 0 & 1 & 0 & 0 & 0 & 0 & 0 & 0 \\
\hline Eptesicus serotinus & 0 & 0 & 0 & 1 & 0 & 0 & 0 & 0 & 0 & 0 & 0 & 0 & 0 \\
\hline Muscardinus avellanarius & 0 & 0 & 0 & 4 & 0 & 2 & 0 & 0 & 0 & 1 & 0 & 2 & \\
\hline Microtus agrestis & 2 & 9 & 0 & 1 & 0 & 0 & 3 & 1 & 0 & 0 & 1 & 0 & 0 \\
\hline Microtus arvalis & 85 & 36 & 48 & 28 & 25 & 8 & 58 & 5 & 16 & 36 & 50 & 99 & 31 \\
\hline Microtus subterraneus & 7 & 7 & 5 & 13 & 10 & 3 & 13 & 0 & 0 & 5 & 0 & 11 & 2 \\
\hline Arvicola amphibius & 0 & 0 & 0 & 0 & 0 & 0 & 1 & 0 & 0 & 0 & 1 & 0 & 1 \\
\hline Myodes glareolus & 7 & 5 & 0 & 3 & 4 & 2 & 7 & 0 & 2 & 0 & 0 & 2 & 0 \\
\hline Apodemus agrarius & 20 & 11 & 3 & 19 & 9 & 5 & 33 & 2 & 10 & 6 & 2 & 8 & 6 \\
\hline Apodemus flavicollis & 1 & 0 & 2 & 1 & 4 & 6 & 4 & 0 & 14 & 13 & 2 & 6 & \\
\hline Apodemus sylvaticus & 4 & 7 & 0 & 9 & 3 & 0 & 3 & 2 & 3 & 2 & 3 & 7 & 2 \\
\hline Apodemus uralensis & 0 & 0 & 0 & 1 & 0 & 0 & 0 & 0 & 0 & 0 & 0 & 0 & 0 \\
\hline Apodemus sp. & 10 & 2 & 4 & 16 & 5 & 4 & 3 & 1 & 5 & 5 & 2 & 9 & 13 \\
\hline Micromys minutus & 0 & 2 & 0 & 0 & 0 & 0 & 0 & 1 & 0 & 0 & 0 & 0 & 0 \\
\hline Mus musculus & 3 & 15 & 1 & 4 & 7 & 1 & 4 & 1 & 5 & 8 & 1 & 4 & 2 \\
\hline Mus spicilegus & 0 & 2 & 3 & 1 & 0 & 2 & 9 & 0 & 11 & 7 & 1 & 0 & 0 \\
\hline Mus sp. & 0 & 0 & 0 & 1 & 0 & 0 & 1 & 0 & 0 & 0 & 0 & 0 & 0 \\
\hline Rattus sp. & 0 & 0 & 0 & 0 & 1 & 0 & 0 & 0 & 0 & 0 & 0 & 0 & 0 \\
\hline Aves (indet.) & 3 & 5 & 0 & 2 & 0 & 1 & 0 & 0 & 0 & 2 & 1 & 1 & 0 \\
\hline Amphibia (Pelobates fuscus) & 0 & 3 & 0 & 2 & 0 & 0 & 0 & 0 & 0 & 0 & 0 & 0 & 0 \\
\hline Amphibia (Rana sp.) & 0 & 0 & 0 & 1 & 0 & 0 & 0 & 0 & 0 & 0 & 0 & 0 & 0 \\
\hline Összesen - Total & 166 & 138 & 77 & 158 & 85 & 49 & 207 & 18 & 69 & 102 & 69 & 171 & 87 \\
\hline
\end{tabular}


3. táblázat: Az emlösfajok mennyiségi megoszlása a vizsgált UTM négyzetekben. Table 3: Quantitative distribution of mammal species in the investigated UTM grids.

\begin{tabular}{lrrrrrr}
\hline Zsákmány - Prey & BT80 & BS79 & BS78 & BS77 & BS89 & BS88 \\
Crocidura leucodon & 1 & 13 & 22 & 34 & 29 & 32 \\
Crocidura suaveolens & 1 & 18 & 73 & 8 & 46 & 95 \\
Sorex araneus & 9 & 5 & 31 & 57 & 21 & 98 \\
Sorex minutus & 2 & 0 & 4 & 22 & 16 & 26 \\
Neomys anomalus & 0 & 1 & 4 & 0 & 3 & 19 \\
Talpa europaea & 0 & 0 & 0 & 0 & 2 & 2 \\
Eptesicus serotinus & 0 & 0 & 0 & 0 & 0 & 1 \\
Muscardinus avellanarius & 0 & 1 & 1 & 0 & 1 & 10 \\
Microtus agrestis & 0 & 1 & 3 & 3 & 5 & 15 \\
Microtus arvalis & 19 & 216 & 195 & 312 & 455 & 440 \\
Microtus oeconomus & 0 & 0 & 0 & 0 & 1 & 0 \\
Microtus subterraneus & 3 & 23 & 18 & 39 & 49 & 69 \\
Arvicola amphibius & 0 & 1 & 0 & 0 & 13 & 3 \\
Myodes glareolus & 1 & 3 & 1 & 12 & 15 & 25 \\
Apodemus agrarius & 2 & 27 & 49 & 84 & 76 & 114 \\
Apodemus flavicollis & 2 & 24 & 29 & 36 & 24 & 57 \\
Apodemus sylvaticus & 2 & 14 & 23 & 60 & 58 & 41 \\
Apodemus uralensis & 0 & 0 & 0 & 0 & 2 & 1 \\
Apodemus sp. & 4 & 33 & 42 & 74 & 58 & 69 \\
Micromys minutus & 1 & 1 & 4 & 8 & 2 & 3 \\
Mus musculus & 1 & 14 & 15 & 41 & 70 & 53 \\
Mus spicilegus & 1 & 24 & 23 & 55 & 8 & 36 \\
Mus sp. & 1 & 1 & 1 & 0 & 1 & 2 \\
Rattus norvegicus & 0 & 9 & 0 & 5 & 1 & 0 \\
Rattus sp. & 0 & 0 & 0 & 0 & 1 & 1 \\
\hline Összesen - Total & 50 & 429 & 538 & 850 & 957 & 1212 \\
\hline & & & & & &
\end{tabular}




\title{
Small mammal fauna survey in north-eastern part of Somogy county (Hungary), based on Barn Owl Tyto alba (Scopoli, 1769) pellet analysis
}

\author{
JENŐ J. PURGER
}

Barn Owl pellets were collected in Somogy county between 1999 and 2009, from 20 localities (investigated area: BT80, BS79, BS78, BS77, BS89 and BS88 UTM grids). In a total of 1570 pellets there were 4127 prey remnants (2.6 was the prey per pellet ratio). Small mammals were dominating (97,8\%). Remnants of birds, amphibians and insects made up $2.2 \%$ of total prey. Mammal prey consisted of Soricomorpha $17.2 \%$ (Crocidura leucodon, Crocidura suaveolens, Sorex araneus, Sorex minutus, Neomys anomalus, Talpa europaea), Chiroptera $0.02 \%$ (Eptesicus serotinus) and Rodentia $82.8 \%$ (Muscardinus avellanarius, Microtus agrestis, Microtus arvalis, Microtus oeconomus,
Microtus subterraneus, Arvicola amphibius, Myodes glareolus, Apodemus agrarius, Apodemus flavicollis, Apodemus sylvaticus, Apodemus uralensis, Micromys minutus, Mus musculus, Mus spicilegus, Rattus norvegicus). The occurrence of 6 small mammal species had been known in the investigated area, while in this paper distribution data are presented for 22 small mammal species. Other important results include the confirmation of the presence of Pygmy Field Mouse (Apodemus uralensis), noted in two locations: Ádánd (BS89) and Nagyberény (BS88), as well as the finding of one specimens of Root Vole (Microtus oeconomus) near the village Ádánd (BS89). 